\title{
Mechanical Properties of Injection Molded Poly(lactic) Acid-Luffa Fiber Composites
}

\author{
Chhatrapati Parida ${ }^{*}$, Sarat Kumar Dash ${ }^{2}$, Pinaki Chaterjee ${ }^{3}$ \\ ${ }^{1}$ Department of Physics, Orissa University of Agriculture and Technology, Bhubaneswar, India \\ ${ }^{2}$ Department of Education in Science and Mathematics, National Council of Educational Research and Training, \\ Bhubaneswar, India \\ ${ }^{3}$ Laboratory for Advanced Research in Polymeric Materials (LARPM), CIPET, Bhubaneswar, India \\ Email: ${ }^{*}$ sivaji 1976@yahoo.co.in
}

Received 27 September 2015; accepted 25 October 2015; published 28 October 2015

Copyright (C) 2015 by authors and Scientific Research Publishing Inc.

This work is licensed under the Creative Commons Attribution International License (CC BY).

http://creativecommons.org/licenses/by/4.0/

(c) (;) Open Access

\begin{abstract}
The influence of cellulose nano fibers extracted from the fruit of luffa cylindrica (LC) on the tensile, flexural and impact properties of composite materials using poly lactic acid (PLA) processed by micro compounding and injection molding was studied. Preliminary results suggested promising mechanical properties. The impact strength, tensile strength and flexural strength of the composites increased with incorporation of very low content of LC fiber up to $2 \mathrm{wt} \%$. But when the wt of LC fiber in the composite increased (5 wt\% and $10 \mathrm{wt} \%$ ), mechanical strength of the composites reduced probably due to agglomeration of cellulose fibers. However, modulus of composites was enhanced with increase in wt of fiber content in the composites. Before reinforcement, the LC fibers were modified with calcium phosphate in order to explore the possibilities of using these composites in biomedical industries. The novelty of this work is that there is no use of compatiblizer and coupling agent during the processing so that the cost of processing is reduced.
\end{abstract}

\section{Keywords}

Luffa Cylindrica, Tensile Stress, Flexural Stress, Impact Strength, Cellulose Fiber

\section{Introduction}

The development of bio composites started in 1980s. Now in the 21st century, increased environmental consciousness demands more renewable based and biodegradable polymers in every sphere. Investigations are still "Corresponding author. 
going on to see that these bio composite materials become fit to the life cycle of nature as well as fit into the system of sustainable development. Composite materials consist of one or more discontinuous phases (reinforcements) embedded in a continuous phase (matrix). Bio composites use natural fiber as reinforcement and renewable polymers as matrix. Fully bio degradable polymers like startch, poly hydroxy alkanoates, poly lactic acid and soy based plastics are currently investigated by many research workers throughout the globe [1] [2]. Some bio degradable polymers like poly lactic acid (PLA), poly glycolic acid (PGA), poly glycolic acid-lactic acid (PGLA) and poly caprolactones (PCL) have been widely used in bio medical industries such as controlled drug delivery, capsules for drug in living organisms, sutures, implants for bones etc. [3]-[6]. Of the above mentioned polymers PLA based composites have been extensively studied by many research workers throughout the globe to explore the ability of PLA to undergo hydrolysis in all environments as well as in human body. PLA is an aliphatic polyester which is obtained by polymerization of lactic acid. Lactic acid possesses two optical isomers in form of $\mathrm{L}$ and D lactide. PLA has advantages like bio compatibility and better thermal processibility compared to other bio polymers. Furthermore, PLA based composites require $25 \%-30 \%$ less energy for processing compared to processing of petroleum based polymer composites [6]. However, PLA is a brittle polymer and hence it needs modification for real practical applications.

Nearly 830 million tons of celluloses are produced each year through photosynthesis. Considering that an average plant contains $40 \%$ cellulose, the annual bio-based resource will be approximately 2000 million dry tons. Cellulose-based polymer composites are characterized by low cost, desirable fiber aspect ratio, low density, high specific stiffness and strength, biodegradability, flexibility during processing with no harm to the equipment, and good mechanical properties. Unlike synthetic fiber, they reduce the wear of machinery. The tensile strength of natural fibers is substantially lower than that of synthetic fibers but the modulus is of the same order of magnitude. However, when the specific modulus (modulus per unit volume) of natural fibers is considered, the natural fibers show values that are comparable to synthetic fibers [7] [8].

Use of cellulose fibers in thermoplastics in general has not been extensive due to their low thermal stability during processing, poor dispersion in the polymer matrix, and limited compatibility with the coupling agents. Good interfacial adhesion between the matrix and fiber transfers the stress from the matrix to the fibers improving the mechanical properties of the composites. Much attention has been focused on modification of the fiber by physical and chemical methods. Therefore, the main objective of our study is to evaluate the mechanical properties of PLA-cellulose based "green" composites. The current research uses the fruit of LC, a common tropical fruit of India, as reinforcement in composite materials producing green composites. The novel aspect is in terms of modification of surface of LC fibers by Ca salts, before using these fibers as reinforcement. The modification of the surface of the fiber by Ca salts opens the possibility in using these composites in bio medical applications. Calcium phosphate based bio-materials are extensively used for bone replacement, dental filling, bone tissue engineering, drug delivery etc. [9].

Kakar et al. in 2015 [10] fabricated biopolymer composites using PLA and heat treated LC fiber as reinforcement processed by hot press compression molding method. The composites with $15 \mathrm{wt} \%$ of heat treated LC fiber showed highest tensile strength and with $20 \mathrm{wt} \%$ untreated LC fiber showed lowest tensile strength. The range of tensile strength of composites reported by them lies between $7.18 \mathrm{MPa}$ and $40.20 \mathrm{MPa}$. Abdulkhani et al. in 2014 [11] fabricated composites using cellulose nano fiber (CNF) and PLA using solvent casting method. $\mathrm{CNF}$ was subjected to esterifcation prior to reinforcement. The results revealed that CNF was uniformly distributed in the PLA matrix at very low content of 1 and $3 \mathrm{wt} \%$. But for higher fiber content of $5 \mathrm{wt} \%$ agglomeration was observed. Maximum tensile strength and tensile modulus were found to be $33.1 \mathrm{MPa}$ and $2.20 \mathrm{GPa}$ resectively for composites having fiber content of $3 \mathrm{wt} \%$. Rice hulls filled PLA bio composites were prepared by compression molding and reported by Srebrenkaska et al. in 2014 [12]. The maximum flexural strength reported was 28.8 MPa for $30 \mathrm{wt} \%$ reinforcement of rice hulls which showed 3.5\% decrease from neat PLA. The maximum flexural modulus was found to be $3.24 \mathrm{GPa}$ at $30 \mathrm{wt} \%$ of fiber content which was $1.25 \%$ higher than neat PLA. PLA/PP polymer blends in various ratio and their composites with sisal fiber were fabricated using melt compounding with twin screw extruder followed by injection molding by Hui et al. in 2013 [13]. The tensile strength and modulus of the composites decreased with increase of PP content in the blend; however, the impact strength was increased with increase in PP content. The strength and modulus of the composites increased with increase in fiber content in the composites. Senai et al. in 2013 [14] prepared bio composites using PLA and empty fruit bunch fiber and reported maximum tensile strength of $53.4 \mathrm{MPa}$, maximum flexural strength of 84.4 $\mathrm{MPa}$ and impact strength of $35.0 \mathrm{MPa}$. 


\section{Experimental}

\subsection{Materials}

Poly lactic acid (PLA) of grade 4042D (molecular weight Mw 600,000), was purchased from Nature Works, USA. The LC fiber was collected from local forest area. The chemicals such as calcium chloride $\left(\mathrm{CaCl}_{2} \cdot 2 \mathrm{H}_{2} \mathrm{O}\right.$, $97 \%)$, di sodium hydrogen phosphate $\left(\mathrm{Na}_{2} \mathrm{HPO}_{4} \cdot 2 \mathrm{H}_{2} \mathrm{O}, 99.5 \%\right)$, sodium hydroxide $(\mathrm{NaOH})$, sodium hypochlorite $(\mathrm{NaClO})$ all of $\mathrm{AR}$ grade were procured from E. Merck, India.

\subsection{Chemical Treatment of LC Fiber}

The fibers of LC were cut into small pieces of length around $2 \mathrm{~cm}$, washed thoroughly to remove impurities like oil, dust etc. These were left for drying at $70^{\circ} \mathrm{C}$ in vacuum oven for 20 minutes. The dried LC fibers were subjected to chemical treatments like treatment with alkali followed by bleaching and acid hydrolysis. For alkali treatment, the LC fibers were soaked in a $5 \% \mathrm{NaOH}$ solution at $80^{\circ} \mathrm{C}$ for $1 \mathrm{~h}$. The hydrophilic nature of the natural fibers leads to poor adhesion between fiber and matrix and this is the main drawback in fabrication of composites. In wet conditions, therefore, such composites show very poor mechanical properties. To improve interfacial bonding and to reduce moisture absorption the LC fibers were subjected to treatment with $\mathrm{NaOH}$ so that the hemicelluloses and lignin present in the fibers were extracted. In this way the number of - $\mathrm{OH}$ groups present in the fiber was reduced leading to increase of hydrophobicity of fibers which strengthen the bonding between fiber and matrix. The alkali treated LC fibers were then bleached with $2 \%$ sodium hypochlorite solution. The mixture was continuously stirred for $2 \mathrm{~h}$ at $80^{\circ} \mathrm{C}$. Bleaching is mainly used to increase whiteness of the fibers. For acid hydrolysis, the bleached LC fiber/water suspension was prepared and kept on an ice bath. $\mathrm{H}_{2} \mathrm{SO}_{4}$ was added slowly under continuous stirring to the suspension placed in an ice water bath, until the final concentration of $60 \% \mathrm{H}_{2} \mathrm{SO}_{4}$ was reached. The obtained suspension was then heated at $45^{\circ} \mathrm{C}$ under continuous stirring for $2 \mathrm{~h}$. In order to remove excess acid the mixture was centrifuged using an ultracentrifuge at $30^{\circ} \mathrm{C}$ for 20 minutes with $7000 \mathrm{rpm}$. Acid hydrolysis leads to the isolation of micro and nano-fibers with a high degree of crystallinity by removing the amorphous regions of the raw cellulose material. Acid hydrolysis decreased the degree of polymerization (DP) and molecular weight of the bleached fibers [15].

\subsection{Modification of Surface of Chemically Treated LC Fiber by Ca Salts}

The dried LC fiber was immersed in $\mathrm{CaCl}_{2}$ solution for $12 \mathrm{~h}$ at room temperature of $30^{\circ} \mathrm{C}$ to deposit $\mathrm{Ca}$ on its surface. The LC fiber modified with $\mathrm{CaCl}_{2}$, were re-immersed in $\mathrm{Na}_{2} \mathrm{HPO}_{4}$ solution for $12 \mathrm{~h}$ at room temperature to deposit compounds of calcium phosphate over it [15].

\subsection{Composite Processing}

Prior to use, the PLA pellets and LC fiber were dried under vacuum at $80^{\circ} \mathrm{C}$ for $24 \mathrm{~h}$. The polymer and fiber were mixed mechanically at $100 \mathrm{rpm}$ with a micro-compounding molding equipment (DSM Micro 15 cc compounding system, DSM research, The Netherlands) at $170^{\circ} \mathrm{C}$ for 10 minutes. This extruder is equipped with a screw of length $150 \mathrm{~mm}, \mathrm{~L} / \mathrm{D}$ of 18 , and net capacity of $15 \mathrm{cc}$. The molten composite samples were transferred after extrusion through a preheated cylinder to the mini injection molder in order to obtain the desired specimen samples for various measurements and analysis. The PLA pellets and LC fibers are mixed in different wt proportion which results in $\mathrm{B}_{0}, \mathrm{~B}_{1}, \mathrm{~B}_{2}$ and $\mathrm{B}_{3}$ samples. $\mathrm{B} 0$ is the neat PLA. In $\mathrm{B}_{1}, \mathrm{~B}_{2}$ and $\mathrm{B}_{3}$ samples the $\mathrm{LC}$ fibers are in the wt ratio $2 \%, 5 \%$ and $10 \%$ respectively. There is no use of compatibilzer and coupling agent during the processing.

\subsection{Wide Angle X-Ray Diffraction}

$\mathrm{Ni}$ filtered $\mathrm{Cu} \mathrm{K} \alpha$ radiation having wavelength $0.1542 \mathrm{~nm}$ was generated at $40 \mathrm{KV}$ and $35 \mathrm{~mA}$ using WXRD/ SHIMADZU/JAPAN. The X-ray diffractograms were recorded from Bragg angle $10^{\circ}$ to $80^{\circ}$ at room temperature of $28^{\circ} \mathrm{C}$ by goniometer equipped with scintillation counter at a scanning speed of $10^{\circ} /$ minute.

\subsection{Mechanical Testing}

The tensile and flexural properties of the composite specimen were measured with Universal testing machine, 
(3382 Instron, UK) according to ASTM D638 and ASTM D790 respectively. System control and data analysis were performed using Datum software. Notched izod impact strength of the specimens was evaluated using an impactometer (Tinius olsen, USA) as per ASTM-D 256 with a notch depth of $2.54 \mathrm{~mm}$ and notch angle of $45^{\circ}$. All results given are the average values of five measurements.

\section{Results \& Discussion}

\subsection{Crystal Structure Analysis}

Figure 1 shows the X-ray diffractogram of the LC fiber obtained after alkali treatment, bleaching and acid hydrolysis modified with calcium salts. Three distinct peaks are found at $15.87^{\circ}, 22.86^{\circ}$ and $34.64^{\circ}$. The peak at $15.87^{\circ}$ corresponds to amorphous cellulose or cellulose II of (101) crystallographic plane whereas the peak at $22.86^{\circ}$ corresponds to crystalline cellulose [cellulose I] of (002) crystallographic plane [15] indicating that the treated LC fibers are partly crystalline and partly amorphous in nature. However, the XRD peak at $34.64^{\circ}$ shows the presence of hydroxy apatite (JCPDS 34-0010) of (300) crystallographic plane in the treated LC fiber [9]. Hydroxy apatite is the polymorph of calcium phosphate and is most extensively used in orthopedics, dentistry and reconstructive surgery.

XRD pattern of injection molded PLA, reinforced with chemically treated LC fiber at $5 \mathrm{wt} \%\left(\right.$ sample $\left.\mathrm{B}_{2}\right)$ is shown in Figure 2. The important sharp crystalline peak in the region around $16^{\circ}$ of treated LC fiber (Figure 1) appears diffused, rather it appears as a board scattering peak. The broad diffused peak origins from amorphous region of PLA. The PLA chains are poorly ordered due to the rapid cooling process during the injection molding. Hence the degree of cystallinity is very poor. PLA exhibits two crystalline structures. Relatively more stable $\alpha$ structure is detected at XRD peak of $14.71^{\circ} \&$ less stable $\beta$ structure at $16.23^{\circ}$. The distinct peaks at $31.38^{\circ} \&$ $45.10^{\circ}$ of XRD spectra correspond to the presence of 300 crystallographic plane of hydroxy apatite.

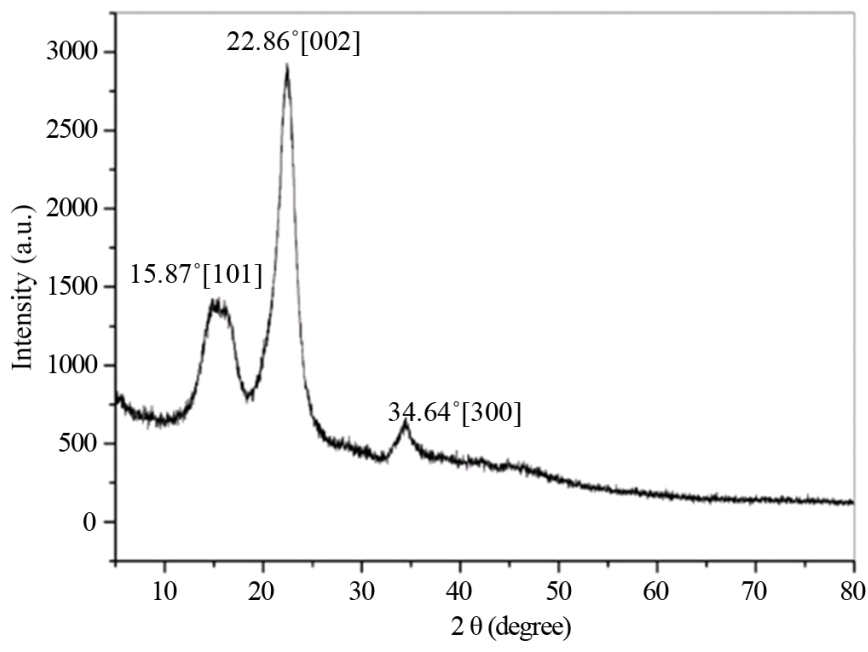

Figure 1. XRD spectra of treated fibers of LC modified by calcium phosphate.

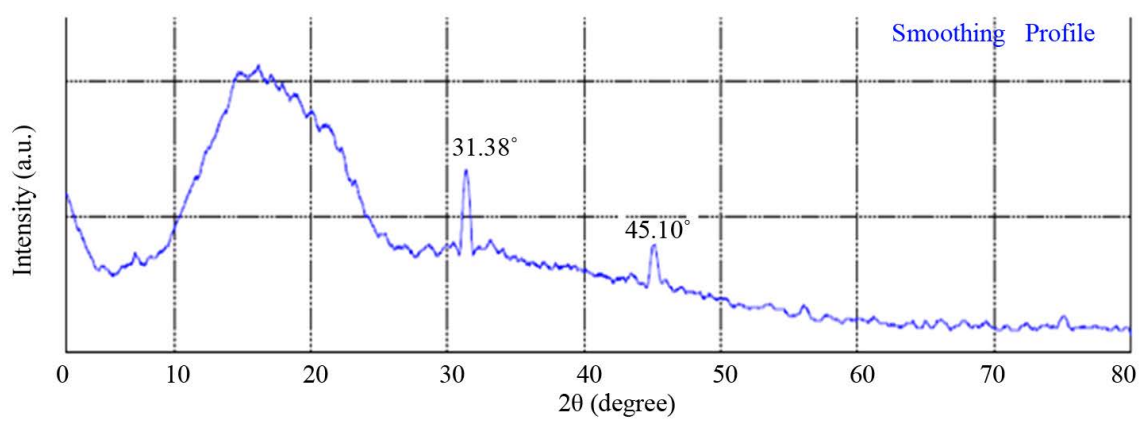

Figure 2. XRD spectra of composite sample B2 (PLA with $5 \mathrm{wt} \%$ of LC fiber). 


\subsection{Effect of LC Fiber Content on Strength of Composites}

Table 1 and Table 2 betoken the values of tensile $\&$ flexural properties of all the composite samples. The tensile strength and flexural strength of neat PLA (sample $\mathrm{B}_{0}$ ) was observed to be $30.425 \mathrm{MPa}$ and $36.12 \mathrm{MPa}$ respectively. When the cellulose fibers extracted from LC fiber were reinforced into PLA matrix, the flexural strength increased to 48.64 MPa, 42.18 MPa and 37.20 MPa for sample $\mathrm{B}_{1}, \mathrm{~B}_{2}$ and $\mathrm{B}_{3}$ respectively. There is a maximum $34.67 \%$ enhancement of flexural strength for sample $B_{1}\left(2 \mathrm{wt} \%\right.$ reinforcement) compared to sample $B_{0}$ (neat PLA). Similarly maximum enhancement of $19 \%$ in tensile strength was reported for sample $\mathrm{B}_{1}$ compared to sample $B_{0}$. Both tensile strength \& flexural strength were found to be maximum for sample $B_{1}(2 \mathrm{wt} \%$ reinforcement) \& decreased with increase in fiber content as observed in sample $\mathrm{B}_{2} \&$ sample $\mathrm{B}_{3}$. The enhancement in tensile and flexural strength can be attributed to distribution of fiber in the matrix and fiber-matrix adhesion. Here it is to be noted that, there are no use of compatibilizers or coupling agents. Though the strength of composite sample $\mathrm{B}_{2} \& \mathrm{~B}_{3}$ are more compared to $\mathrm{B}_{0}$ but less than that of sample $\mathrm{B}_{1}$. There may be agglomeration of fiber due to increase in wt of fiber in the composite sample $\mathrm{B}_{2}$ and $\mathrm{B}_{3}$. As the wt of reinforced fiber increases in the matrix, there is more fiber surface, which needs to be wetted. But there is less polymer surface for sufficient stress transfer. Hence the mechanical strength reaches a plateu value for sample $\mathrm{B}_{1} \&$ starts decreasing with further addition of fiber in sample $\mathrm{B}_{2}$ and $\mathrm{B}_{3}$. Figure 3 shows the variation of tensile stress with different fiber loading.

\subsection{Effect of Fiber Loading on Modulus of Composites}

The natural fibers are rigid in nature and their rigidity is more compared to neat PLA which leads to increase in modulus of the composites with the incorporation of fibers. Hence reinforcement of LC fibers in to the PLA matrix will enhance the modulus of all the composite samples. The ductile behavior of all the composite samples, $\mathrm{B}_{1}, \mathrm{~B}_{2}, \mathrm{~B}_{3}$ were found to be reduced due to incorporation of rigid fibers. Data in Table 1 and Table 2 show that modulus of all composite samples $\left(\mathrm{B}_{1}, \mathrm{~B}_{2} \& \mathrm{~B}_{3}\right)$ are enhanced compared to modulus of neat PLA (sample $\left.\mathrm{B}_{0}\right)$. Again with increase in wt of fiber content in the composites, modulus was also increased. Maximum tensile modulus was observed for sample $\mathrm{B}_{3}$ with $33.65 \%$ enhancement \& maximum flexural modulus was observed for sample $\mathrm{B}_{2}$ with $22.10 \%$ improvement. Figure 4 shows the variation of flexural modulus with different fiber loading.

\subsection{Effect of Fiber Content on Impact Properties}

Impact strength of composite materials are indicators of toughness of the materials. PLA is a brittle polymer and the low impact strength of PLA polymers is the main drawback for technical applications. Therefore most current

Table 1. Values of tensile stress at maximum load, tensile strain at yield, tensile modulus and energy at maximum load of composites and matrix at different fiber loadings.

\begin{tabular}{ccccc}
\hline Sample & Tensile stress at maximum load (MPa) & Tensile strain at yield (\%) & Tensile modulus (MPa) & Energy at maximum load (Joules) \\
\hline $\mathrm{B}_{0}$ & 30.425 & 1.32 & 2242.61 & 1.1234 \\
$\mathrm{~B}_{1}(2 \%)$ & 36.447 & 1.58490 & 2827.61997 & 1.29249 \\
$\mathrm{~B}_{2}(5 \%)$ & 35.603 & 1.44661 & 2930.452 & 1.14323 \\
$\mathrm{~B}_{3}(10 \%)$ & 33.298 & 1.38646 & 2997.452 & 1.03722 \\
\hline
\end{tabular}

Table 2. Values of flexural stress at maximum load, flexural strain at yield, flexural modulus and energy at maximum load of composites and matrix at different fiber loadings.

\begin{tabular}{cccc}
\hline Sample & Flexural stress at maximum flexure load (MPa) & Flexural strain at yield (\%) & Flexural modulus (MPa) \\
\hline $\mathrm{B}_{0}$ & 36.12 & 1.12 & 3226.12 \\
$\mathrm{~B}_{1}(2 \%)$ & 48.64381 & 1.43 & 3624.819 \\
$\mathrm{~B}_{2}(5 \%)$ & 42.182 & 1.151 & 3939.352 \\
$\mathrm{~B}_{3}(10 \%)$ & 37.206 & 1.16 & 3765.363 \\
\hline
\end{tabular}




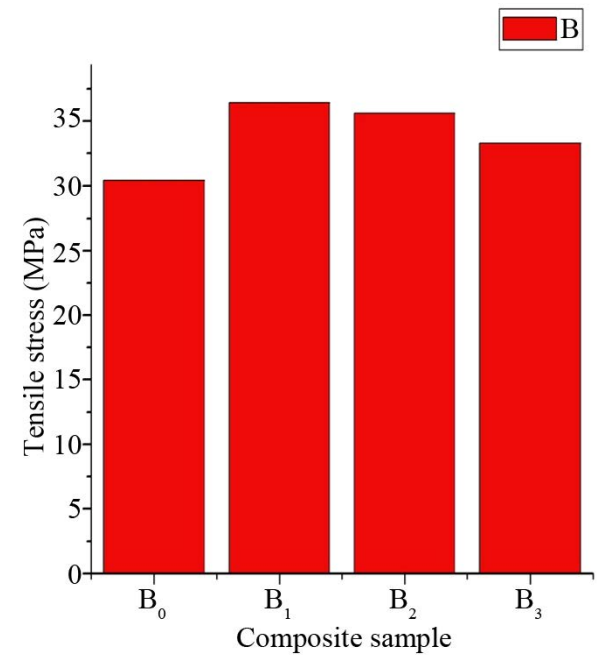

Figure 3. Variation of tensile stress with fiber loading for $\mathrm{B}_{0}, \mathrm{~B}_{1}, \mathrm{~B}_{2}$ and $\mathrm{B}_{3}$ samples.

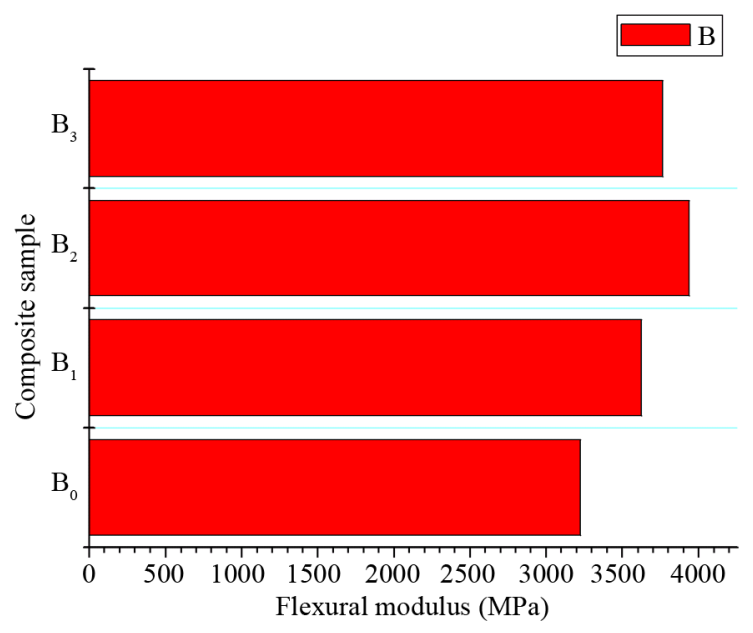

Figure 4. Variation of flexural modulus with fiber loading for $\mathrm{B}_{0}, \mathrm{~B}_{1}, \mathrm{~B}_{2}$ and $\mathrm{B}_{3}$ samples.

research on PLA bio composite seeks to improve the impact property to a level that satisfies some specific applications. Data in Table 3 represent the effect of fiber content in the composites on the notched izod impact strength of the composite samples. As seen from Table 3, addition of chemically treated LC fiber to PLA matrix, did not significantly enhanced the impact strength of the composite samples. However, with reinforcement of 2 $\mathrm{wt} \%$ (sample $\mathrm{B}_{1}$ ) highest impact strength of $28.1937 \mathrm{~J} / \mathrm{m}$ was achieved with $24.93 \%$ improvement compared to neat PLA. Increase of fiber content beyond $2 \mathrm{wt} \%$ as in composite sample $\mathrm{B}_{2}$ and $\mathrm{B}_{3}$, did not significantly contribute to the capacity of composites to absorb energy under sudden impact. Higher wt of LC fiber initiates stress concentration region, which requires less energy for initiating cracks. The origin of stress concentration region may be due to defects in composites, presence of voids and lack of adhesion between fiber and matrix. When wt of fiber is more in the matrix, and a sudden load is applied, the stress is actually transferred from PLA matrix to LC fiber. Here LC fiber acts as a barrier to transfer the stress load from small portions of PLA matrix as in composite sample $\mathrm{B}_{2}$ and $\mathrm{B}_{3}$. So less energy is absorbed \& cracks are formed rather than fiber pull out. The inherent density of cellulose is higher than that of PLA. Hence when composites are formed, there is increase of density and simultaneous increase of void volume, with increase in fiber content. Thus the impact strength of composite samples $B_{2}$ and $B_{3}$ shows negative results with $33.81 \%$ reduction in sample $B_{2}$ and $34 \%$ reduction in sample $\mathrm{B}_{4}$ compared to neat PLA (sample $\mathrm{B}_{0}$ ). 
Table 3. Values of impact break values and impact strength of composites and matrix at different fiber loadings.

\begin{tabular}{ccc}
\hline Sample & Break value (in J) & Strength $(\mathrm{J} / \mathrm{m})$ \\
\hline $\mathrm{B}_{0}$ & 0.0564 & 22.6543 \\
$\mathrm{~B}_{1}$ & 0.0902 & 28.1937 \\
$\mathrm{~B}_{2}$ & 0.0481 & 15.0614 \\
$\mathrm{~B}_{3}$ & 0.0364 & 15.0181 \\
\hline
\end{tabular}

\section{Conclusion}

A maximum of $19 \%$ enhancement in tensile strength and a maximum of $34.66 \%$ enhancement in flexural strength were reported for sample $\mathrm{B}_{1}(2 \mathrm{wt} \%)$ compared to that of the neat PLA (sample $\left.\mathrm{B}_{0}\right)$. This enhancement was achieved only with reinforcement of very low content of treated LC fiber in the composites and without using any compatibilizer or coupling agents, thereby reducing the cost of processing leading to very light wt materials having high strength to mass ratio. Use of DSM micro compounding molding techniques reduced the experimental processing time. The present work transformed the low priced, readily available and agricultural product LC fiber into a high value product with low cost and low processing time. The maximum tensile stress was reported to be $36.447 \mathrm{Mpa}$ and this value is comparable to tensile stress of a soft tissue, articular cartilage [16]. The composite may be further investigated to fit the bone plate for external bone implant. Research on using these cellulose materials in pharmaceutical applications like drug delivery, scaffolds for tissue regeneration etc. may be attempted. The future work will also include efforts to evaluate the biodegradability of these composites.

\section{Acknowledgements}

The authors thank Laboratory of Advanced Research in Polymeric Materials (LARPM), CIPET, Govt. of India for providing facilities and equipments for making this study.

\section{References}

[1] Kalia, S., Dufresne, A., Cherian, B.M., Kaith, B.S., Avérous, L., Njuguna, J., Nassiopoulos, E. (2011) Cellulose-Based Bio- and Nanocomposites: A Review. International Journal of Polymer Science, Article ID 837875, 35 p.

[2] John, M.J. and Thomas, S. (2008) Biofibres and Biocomposites. Carbohydrate Polymers, 71, 343-364. http://dx.doi.org/10.1016/j.carbpol.2007.05.040

[3] Zenkiewicz, M. and Richert, J. and Różański, A. (2010) An Effect of Blow Moulding Ratio on Barrier Properties of Polylactide Nanocomposite Films. Polymer Testing, 29, 251-257. http://dx.doi.org/10.1016/j.polymertesting.2009.11.008

[4] Bhatia, A., Gupta, R., Bhattacharya, S. and Choi, H. (2010) Effect of Clay on Thermal, Mechanical and Gas Barrier Properties of Biodegradable Poly(lactic acid)/Poly(butylene succinate) (PLA/PBS) Nanocomposites. International Polymer Processing, 25, 5-14. http://dx.doi.org/10.3139/217.2214

[5] Martino, V.P., Ruseckaite, R.A., Jiménez, A. and Averous, L. (2010) Correlation between Composition, Structure and Properties of Poly(lactic acid)/Polyadipate-Based Nano-Biocomposites. Macromolecular Materials and Engineering, 295, 551-558. http://dx.doi.org/10.1002/mame.200900351

[6] Rasala, R.M., Janorkarc, A.V. and Hirta, D.E. (2010) Poly(lactic acid) Modifications. Progress in Polymer Science, 35, 338-356. http://dx.doi.org/10.1016/j.progpolymsci.2009.12.003

[7] Bledzki, A.K. and Gassan, J. (1999) Composites Reinforced with Cellulose Based Fibres. Progress in Polymer Science, 24, 221-274. http://dx.doi.org/10.1016/S0079-6700(98)00018-5

[8] Sreekala, M.S., Kumaran, M.G. and Thomas, S. (1997) Green Composites from Natural Rubber and Oil. Journal of Applied Polymer Science, 66, 821-835. http://dx.doi.org/10.1002/(SICI)1097-4628(19971031)66:5<821::AID-APP2>3.0.CO;2-X

[9] Mazali, I.O. and Alves, O.L. (2005) Morphosynthesis: High Fidelity Inorganic Replica of the Fibrous Network of Loofa Sponge. Annals of the Brazilian Academy of Sciences, 77, 25-31.

[10] Kakar, A., Jayamani, E., Heng, S.K., Bakri, M.K.B. and Hamdan, S. (2015) Optimization of Hot Press Compression Molding and Fabrication of Poly Lactic Acid (PLA) Luffa Biocomposites for Biomedical Applications. Australian 
Journal of Basic and Applied Sciences, 9, 105-112.

[11] Abdulkhani, A., Hosseinzadeh, J., Ashori, A., Dadashi, S. and Takzare, Z. (2014) Preparation and Characterization of Modified Cellulose Nanofibers Reinforced Polylactic Acid Nanocomposite. Polymer Testing, 35, 73-79. http://dx.doi.org/10.1016/j.polymertesting.2014.03.002

[12] Srebrenkoska, V., Gaceva, G.B. and Dimesk, D. (2014) Biocomposites Based on Polylactic Acid and Their Thermal Behavior after Recycling. Macedonian Journal of Chemistry and Chemical Engineering, 33, 277-285.

[13] Hui, Z.-P., Sudhakara, P., Wang, Y.-Q., Kim, B.-S. and Song, J.-I. (2013) Manufacturing and Mechanical Properties of Sisal Fiber Reinforced Hybrid Composites, Composites Research, 26, 273-278. http://dx.doi.org/10.7234/composres.2013.26.5.273

[14] Senawi, R., Alauddin, S.M., Saleh, R.M. and Shueb, M.I. (2013) Polylactic Acid/Empty Fruit Bunch Fiber Biocomposite: Influence of Alkaline and Silane Treatment on the Mechanical Properties. International Journal of Bioscience, Biochemistry and Bioinformatics, 3, 59-61. http://dx.doi.org/10.7763/IJBBB.2013.V3.164

[15] Parida, C., Dash, S.K. and Das, S.C. (2015) Effect of Fiber Treatment and Fiber Loading on Mechanical Properties of Luffa-Resorcinol Composites. Indian Journal of Materials Science, Article ID: 658064.

[16] Ramakrishna, S., Mayer, J., Wintermantel, E. and Leong, K.W. (2001) Biomedical Applications of Polymer-Composite Materials: A Review. Composites Science and Technology, 61, 1189-1224. http://dx.doi.org/10.1016/S0266-3538(00)00241-4 